\title{
Use of the XFEM for the design of adhesively-bonded T-joints
}

\author{
F.J.P. Moreira \\ Departamento de Engenharia Mecânica, Instituto Superior de Engenharia do Porto, Instituto Politécnico do Porto, Portugal \\ filipejpmoreira08@gmail.com
}

R.D.S.G. Campilho

Departamento de Engenharia Mecânica, Instituto Superior de Engenharia do Porto, Instituto Politécnico do Porto, Portugal

INEGI - Pólo FEUP

raulcampilho@gmail.com, bttps://orcid.org/0000-0003-4167-4434

\begin{abstract}
The use of adhesive bonds greatly increased in industrial applications, as they have multiple advantages compared to other more traditional bonding methods (fastened, welded and riveted joints). The number of approaches to predict the strength of adhesive joints has increased over the years. The eXtended Finite Element Method (XFEM) is a recent variant of the (Finite Element Method) FEM to model damage growth in structures, although it is yet seldom studied within the context of bonded joints. This work consists of an experimental and XFEM analysis of aluminium alloy T-joints, adhesively-bonded with three adhesive types. A parametric study is undertaken regarding the curved adherends' thickness $\left(t_{\mathrm{P} 2}\right)$, with values between 1 and $4 \mathrm{~mm}$. The adhesives Araldite ${ }^{\circledR}$ AV138 (strong but brittle), Araldite ${ }^{\circledR} 2015$ (less strong but moderately ductile) and the Sikaforce ${ }^{\circledR}$ 7752 (with the smallest strength but highly ductile) were tested. A comparative analysis between the different joints conditions was undertaken by plotting peel $\left(\sigma_{y}\right)$ and shear $\left(\tau_{\mathrm{xy}}\right)$ stresses, and analysing the damage variable. The XFEM predictive capabilities were tested with different damage initiation and propagation criteria. It was found that, provided that the modelling conditions are properly set, accurate numerical results can be found.
\end{abstract}

KEYWORDS. Fracture; Finite element analysis; eXtended Finite Element Method; Bonded joint.

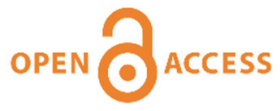

Citation: Moreira, F.J.P., Campilho, R.D.S.G., Use of the XFEM for the design of adhesively-bonded T-joints, Frattura ed Integrità Strutturale, 49 (2019) 435-449.

Received: 30.11 .2018

Accepted: 14.05.2019

Published: 01.07.2019

Copyright: (C) 2019 This is an open access article under the terms of the CC-BY 4.0, which permits unrestricted use, distribution, and reproduction in any medium, provided the original author and source are credited.

\section{INTRODUCTION}

he use of adhesive bonds greatly increased in industrial applications, as they have multiple advantages compared to other more traditional bonding methods (fastened, welded and riveted joints). The aeronautical, naval, automotive and aerospace industries are good examples where adhesive joints are widely applied. More uniform distribution of 
stresses, ease of manufacture, possibility of joining different materials and low cost are the main advantages of adhesive bonds. The main disadvantages are related to the requirement of surface preparation, low peel strength and difficulties in quality control and safety. The most common adhesive joint configurations are single-lap joints (SLJ), double-lap joints (DLJ) and scarf joints [1]. SLJ are the most common. However, they develop major $\sigma_{\mathrm{y}}$ peak stresses. DLJ are more difficult to manufacture but, on the other hand, $\sigma_{\mathrm{y}}$ stresses greatly diminish. Scarf joints are highly efficient when compared to SLJ because of the reduction of stress concentrations [1]. Although these types of joints are the most used in the industry, other types of joints have specific applications. Stepped-lap configurations can be used in composite joining due to the easiness to make the step design during the materials' fabrication process [2]. T-joints find application in the naval and aeronautical industries. In the naval industry, they allow joining panels with the hull [3] and the fiberglass hull with anti-flood panels [4]. In the aeronautical industry, they are used to join wing panels and fuselage sections [5]. Several works were carried out to evaluate T-joints, using either analytical or numerical techniques $[6,7]$.

The number of approaches to predict the strength of adhesive joints has increased over the years. Actually, analytical and numerical techniques have become more and more refined and with higher accuracy. Numerical methods are typically founded on the FEM. The FEM allows modelling complex geometries with high precision, due to the computational advancements and Computer Aided Engineering (CAE) tools. Within this scope, the use of Continuum Mechanics supposes using the obtained stresses or strains, whose maximum values are used in appropriate failure criteria to assess failure. However, this technique has limited applicability because of stress singularities (which make the predictions dependent on the applied mesh) and neglecting of fracture mechanics concepts [8]. Actually, in a bonded joint FEM analysis, stresses near the singular regions increase with the mesh refinement, making convergence impossible [9]. Traditional Fracture Mechanicsbased techniques can be applied to the study of the behaviour of structures that contain defects, such as cracks. These cracks can result from stress concentrations, usually located in holes, notches or interfaces between different materials. However, it is not mandatory that the structures to be analysed already have cracks, which is a limitation of this method [10]. Cohesive Zone Models (CZM) were developed to describe damage under static loads in the cohesive process zone around the crack tip. They are based on cohesive elements, which allow connecting solid elements of two-dimensional (2D) and threedimensional (3D) structures, using pre-established traction-separation laws [11]. CZM were tested and optimized to promote structural damage initiation and crack propagation simulations on cohesive and interfacial fracture problems, and delamination in composites. The use of CZM to model structures enables to create one or more regions or interfaces in which damage nucleation and growth is made possible by the softening and release of homologous nodes of the cohesive elements [12]. FEM simulations based on continuum mechanics wrongly consider that the solid elements undergo plasticization without taking damage. Damage mechanics simulations work by inducing damage to the elements through the reduction of transmitted loads between solid elements. Thus, it is possible to perform the simulation of crack growth, in which the cracks can assume a pre-defined trajectory or an arbitrary trajectory within a finite region [8]. In Damage Mechanics, a damage parameter is established to cause a change in the response of the constituent materials through the depreciation of the strength or stiffness, as occurs in adhesive layers, or in composite delaminations, to model damage during loading $[13,14]$. The insertion of a damage variable in the constitutive law of the material enables simulating damage before and after crack nucleation. Two types of damage variables can be introduced in the models: variables that empirically depreciate the properties of the materials, without any relation to the damage mechanism, and variables that have a physical significance, by directly relating to the observed type of damage (for example the size of porosities or micro-cavities) [15]. The growth of damage is usually ruled by the load function for static simulations [16] and as a function of the number of cycles for fatigue modelling $[17,18]$. The XFEM is a recent variant of the FEM to model damage growth in structures, although it is yet seldom studied within the context of bonded joints. This method uses damage laws to predict fracture, based on strength concepts to infer damage initiation of damage and deformations for failure. Comparing the XFEM with CZM, the XFEM has the clear advantage of not requiring the crack to follow a predefined path by the user. This is because crack propagation occurs freely inside the material, without the geometry of the discontinuities being coincident with the mesh or the necessity to correct the mesh in the crack vicinity [19]. The XFEM is based on the concept of partition of unity, and its implementation in the FEM can be accomplished by introducing local enrichment functions for the displacements near the crack tip, allowing damage to grow and respective separation between the cracked faces [20]. Mubashar et al. [21] carried out a study on the damage and failure modelling of adhesively-bonded SLJ with spew fillets at the overlap ends, combining two methods: XFEM (to perform the modelling of the crack in the fillet region where the crack path is unknown) and CZM (applied to model crack progression and damage along the adhesive bond interface). The numerical analysis was performed in Abaqus $^{\circledR}$. Aluminium alloy 2024 T3 adherends were bonded with the epoxy adhesive FM73-M, and the adhesive was modelled with elastoplastic properties, obtained in tensile tests. This work allowed to conclude that the XFEM is capable of predicting, with a high degree of precision, the crack onset location and path within the spew fillet. Moreover, it is possible to combine the XFEM with CZM to more accurately predict crack initiation and growth in bonded joints, 
including at the interface. However, this technique is limited by the existence of a potential discontinuity in the crack at the XFEM-CZM transition. Stuparu et al. [22] conducted a study on the combined use of CZM and XFEM for the strength prediction of bonded joints. The SLJ configuration was tested, with aluminium adherends and the adhesive Araldite ${ }^{\circledR}$ AV138. The following parameters were used: adherends' thickness $\left(t_{\mathrm{p}}\right)$ of $5 \mathrm{~mm}$, adhesive thickness $\left(t_{\mathrm{A}}\right)$ of 1,3 and $5 \mathrm{~mm}$, overlap length $\left(L_{0}\right)$ of $20 \mathrm{~mm}$ and sample width $(B)$ of $25 \mathrm{~mm}$. The numerical analysis was done in Abaqus ${ }^{\circledR}$. The XFEM was used to simulate failure within the adhesive, considering a strain criterion (less mesh dependent than stress criteria) for crack onset prediction. Thus, crack initiation/propagation will always take place orthogonally to the maximum principal strains. On the other hand, CZM was equated to simulate an interfacial failure between the adhesive and adherends. Different $t_{\mathrm{A}}$ and the positions of initial bonding flaws were tested, resulting in modifications of the XFEM crack trajectories, eventually attaining the interface. It was shown that the use of XFEM is well complemented by CZM to promote crack growth after the XFEM crack attained the interface.

This work consists of an experimental and XFEM analysis of aluminium alloy T-joints, adhesively-bonded with three adhesive types. A parametric study is undertaken regarding ter, with values between 1 and $4 \mathrm{~mm}$. The adhesives Araldite ${ }^{\circledR}$ AV138 (strong but brittle), Araldite ${ }^{\circledR} 2015$ (less strong but moderately ductile) and the Sikaforce ${ }^{\circledR} 7752$ (with the smallest strength but highly ductile) were tested. A comparative analysis between the different joints conditions was undertaken by plotting $\sigma_{\mathrm{y}}$ and $\tau_{\mathrm{xy}}$ stresses, and analysing the damage variable. The XFEM predictive capabilities were tested with different damage initiation and propagation criteria.

\section{EXPERIMENTAL WORK}

\section{Adherends and adhesives}

7 he T-joints are made of three AW6082 T651 aluminium alloy aluminium adherends bond together. This is a highstrength alloy, characterized in a previous work [23]. Fig. 1 shows typical stress-strain $(\sigma-\varepsilon)$ curves of this aluminium alloy, whose relevant properties in bulk tensile testing are: Young's modulus $(E)$ of $70.1 \pm 0.8 \mathrm{GPa}$, tensile yield stress

$\left(\sigma_{\mathrm{y}}\right)$ of $261.7 \pm 7.7 \mathrm{MPa}$, tensile strength $\left(\sigma_{\mathrm{f}}\right)$ of $324.0 \pm 0.2 \mathrm{MPa}$ and tensile failure strain $\left(\varepsilon_{\mathrm{f}}\right)$ of $21.7 \pm 4.2 \%$.

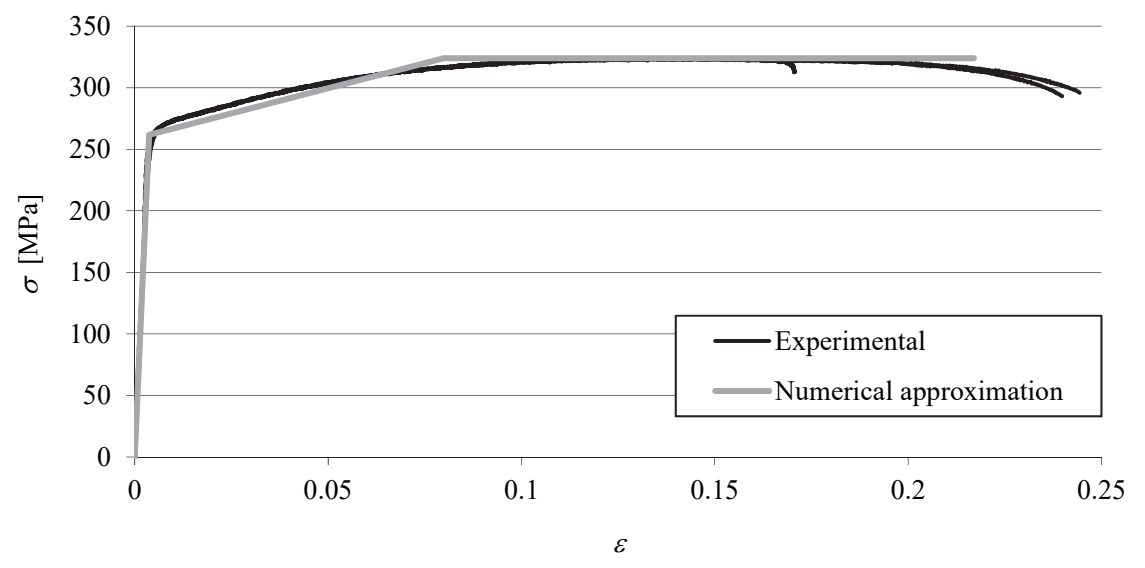

Figure 1: Experimental and numerical $\sigma-\varepsilon$ curves of the aluminium.

The following adhesives were tested in the T-joint configuration: Araldite ${ }^{\circledR}$ AV138 (brittle epoxy), Araldite ${ }^{\circledR} 2015$ (ductile epoxy) and the Sikaforce ${ }^{\circledR} 7752$ (high-elongation polyurethane). All adhesives were formerly tested and the respective properties detailed in references [23-25]. The tensile mechanical properties $\left(E, \sigma_{\mathrm{y}}, \sigma_{\mathrm{f}}\right.$ and $\left.\varepsilon_{\mathrm{f}}\right)$ resulted from bulk tests to dogbone specimens. The fabrication process for these specimens followed the indications stipulated in the NF T 76-142 French standard. The shear mechanical properties (Shear modulus $-G$, shear yield stress $-\tau_{\mathrm{y}}$, shear strength $-\tau_{\mathrm{f}}$ and shear failure strain $-\gamma_{\mathrm{f}}$ ) were estimated by Thick Adherend Shear Tests (TAST). In this case, the 11003-2:1999 ISO standard was considered for fabrication and testing protocols. The TAST specimens were made with DIN Ck 45 steel adherends, and curing was undertaken in a rigid mould to guarantee that the cured specimens are aligned [26]. The toughness properties of the adhesives were estimated with the Double-Cantilever Beam (DCB) test (tensile fracture toughness or GIC) and the EndNotched Flexure (ENF) test (shear fracture toughness or $G_{\text {IIC }}$ ). Tab. 1 gives an overview of the obtained data, which will 
be used in this work for input in the numerical simulations. To be noted that the values of yield stress were defined considering a plastic strain of $0.2 \%$.

\begin{tabular}{lccc}
\hline \multicolumn{1}{c}{ Property } & AV138 & $\mathbf{2 0 1 5}$ & $\mathbf{7 7 5 2}$ \\
Young's modulus, $E[\mathrm{GPa}]$ & $4.89 \pm 0.81$ & $1.85 \pm 0.21$ & $0.49 \pm 0.09$ \\
Poisson's ratio, $v$ & $0.35^{\mathrm{a}}$ & $0.33 \mathrm{a}$ & $0.30 \mathrm{a}$ \\
Tensile yield stress, $\sigma_{\mathrm{y}}[\mathrm{MPa}]$ & $36.49 \pm 2.47$ & $12.63 \pm 0.61$ & $3.24 \pm 0.48$ \\
Tensile failure strength, $\sigma_{\mathrm{f}}[\mathrm{MPa}]$ & $39.45 \pm 3.18$ & $21.63 \pm 1.61$ & $11.48 \pm 0.25$ \\
Tensile failure strain, $\mathcal{E}_{\mathrm{f}}[\%]$ & $1.21 \pm 0.10$ & $4.77 \pm 0.15$ & $19.18 \pm 1.40$ \\
Shear modulus, $G[\mathrm{GPa}]$ & $1.81^{\mathrm{b}}$ & $0.70 \mathrm{~b}$ & $0.19 \mathrm{~b}$ \\
Shear yield stress, $\tau_{\mathrm{y}}[\mathrm{MPa}]$ & $25.1 \pm 0.33$ & $14.6 \pm 1.3$ & $5.16 \pm 1.14$ \\
Shear failure strength, $\tau_{\mathrm{f}}[\mathrm{MPa}]$ & $30.2 \pm 0.40$ & $17.9 \pm 1.8$ & $10.17 \pm 0.64$ \\
Shear failure strain, $\gamma_{\mathrm{f}}[\%]$ & $7.8 \pm 0.7$ & $43.9 \pm 3.4$ & $54.82 \pm 6.38$ \\
Toughness in tension, $G_{\mathrm{IC}}[\mathrm{N} / \mathrm{mm}]$ & $0.20^{\mathrm{c}}$ & $0.43 \pm 0.02$ & $2.36 \pm 0.17$ \\
Toughness in shear, $G_{\mathrm{IIC}}[\mathrm{N} / \mathrm{mm}]$ & $0.38^{\mathrm{c}}$ & $4.70 \pm 0.34$ & $5.41 \pm 0.47$ \\
\hline${ }^{a}$ manufacturer's data \\
${ }^{\mathrm{b}}$ Estimated from the Hooke's law using $E$ and $v$ & & & \\
${ }^{\mathrm{c} e s t i m a t e d ~ i n ~ C a m p i l h o ~ e t ~ a l . ~}[23]$ & & &
\end{tabular}

Table 1: Properties of the adhesives Araldite ${ }^{\circledR}$ AV138, Araldite $^{\circledR} 2015$ and Sikaforce ${ }^{\circledR} 7752$ [23-25].

\section{Experimental details}

Fig. 2 represents the geometry and dimensions of the T-joints. The relevant dimensions are the following: $L_{0}=25 \mathrm{~mm}$, $B=25 \mathrm{~mm}$, base length $L_{T}=80 \mathrm{~mm}$, base thickness $t_{\mathrm{p} 1}=3 \mathrm{~mm}$, t卬2 $=1,2,3$ and $4 \mathrm{~mm}$, L-part length $L_{\mathrm{A}}=60 \mathrm{~mm}$, L-part radius $R=5 \mathrm{~mm}$ and $t_{\mathrm{A}}=0.2 \mathrm{~mm}$. Specimen fabrication was initiated by cutting/bending the adherends to the respective shapes. The straight adherend, used as the specimen base, is obtained by cutting, in an automated cutter, a bar to the final dimensions. The L-parts were subjected to an identical procedure, but then they were manually bent in a press, such that the end surfaces were at an angle of $90^{\circ}$, and applying a tool with the chosen R, to produce the geometry depicted in Fig. 2. The surface preparation before bonding consisted of manually increasing the roughness by sanding using emery paper with coarse grain (60 grit), followed by wiping with cleaning agent (acetone) to eliminate dust and oxides, thus achieving a strong bond. Joining of the different parts was accomplished in a jig that positioned the three adherends in the layout of Fig. 2 and enabled keeping this position throughout the entire adhesive hardening process. To assure the specified $t_{\mathrm{A}}$, steel spacers with identical thickness to $t_{\mathrm{A}}$ were inserted at the edges of the bonded parts are removed after adhesive curing. Before placing the spacers, they were initially coated with Loctite ${ }^{\circledR}$ Frekote $770 \mathrm{NC}$ demoulding agent, to guarantee easy removal after the adhesive has cured, which is essential to prevent damage to the cured adhesive layers. With the specimens in position after depositing the adhesive, and with the spacers providing the correct offset between adherends, grips were used to apply pressure to the set and enable curing to take place. This process was accomplished during a one-week period. The final step consisted of trimming the excess cured adhesive by milling. As a result of this set of operations, it was possible to obtain a good representation of the theoretical geometry of Fig. 2, with emphasis to the bondline end geometry positioned at $x / L_{0}=0$ ( $x$ is the horizontal coordinate initiating at the bondline end). The specimens were tested as depicted in Fig. 2, i.e. by clamping the edges of the straight adherend and pulling in peel while transversely restraining the upper joint edge. This was done in a Shimadzu AG-X 100 testing machine, equipped with a $100 \mathrm{kN}$ load cell, at an approximate temperature of $20^{\circ} \mathrm{C}$ and testing speed of $1 \mathrm{~mm} / \mathrm{min}$. Five specimens were fabricated and tested for each joint type. A minimum of 4 valid tests was always assured for each joint type. 


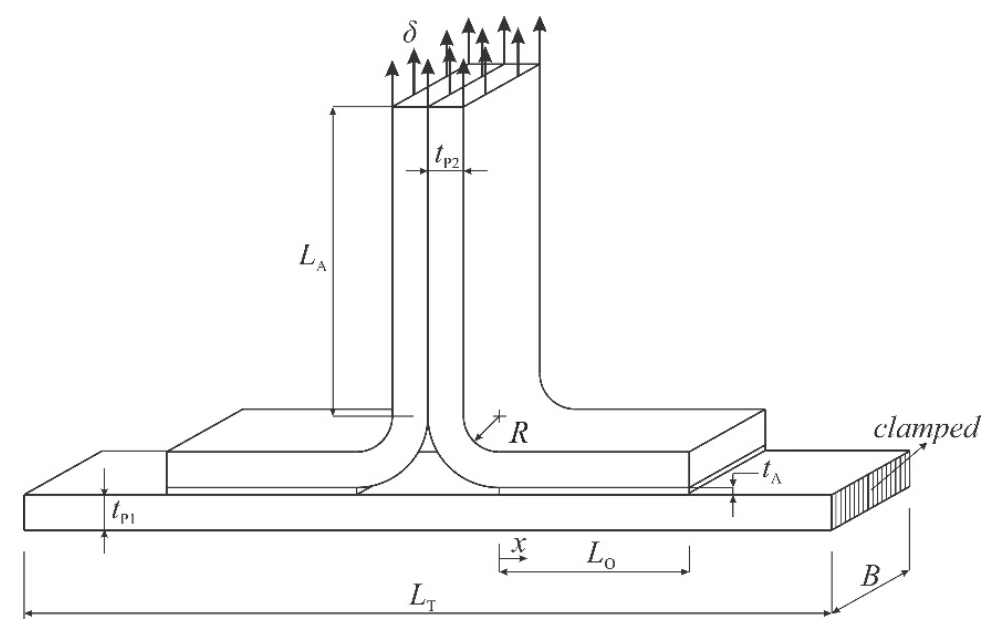

Figure 2: Representative geometry and dimensions of the T-joints.

\section{NUMERICAL WORK}

\section{Numerical simulation details}

he analysis performed in Abaqus ${ }^{\circledR}$ was 2D, considering a geometrically non-linear FEM formulation. The aluminium adherends (both base and L-parts) were modelled as solids with the plastic behaviour defined in a previous work for the same material [27]. The adhesive layer was also modelled with solid elements, but with enriched XFEM formulation. The XFEM model is presented in the next Section. In all cases, 4-node solid elements with plane-strain conditions were used (with Abaqus ${ }^{\circledR}$ reference CPE4). A perfect adhesion was considered in the models between the adherends and adhesive, since the models were built as a single part with different partitions and materials. Two types of meshes were applied: a more refined mesh to perform a stress analysis in the elastic domain, such that the stress plots are accurate, and a less refined mesh to promote the XFEM failure analysis. Fig. 3 shows an example of mesh refinement for a $\mathrm{T}$-joint with $t_{2}=1 \mathrm{~mm}$, with details at the loaded overlap edge for the stress and failure analyses.

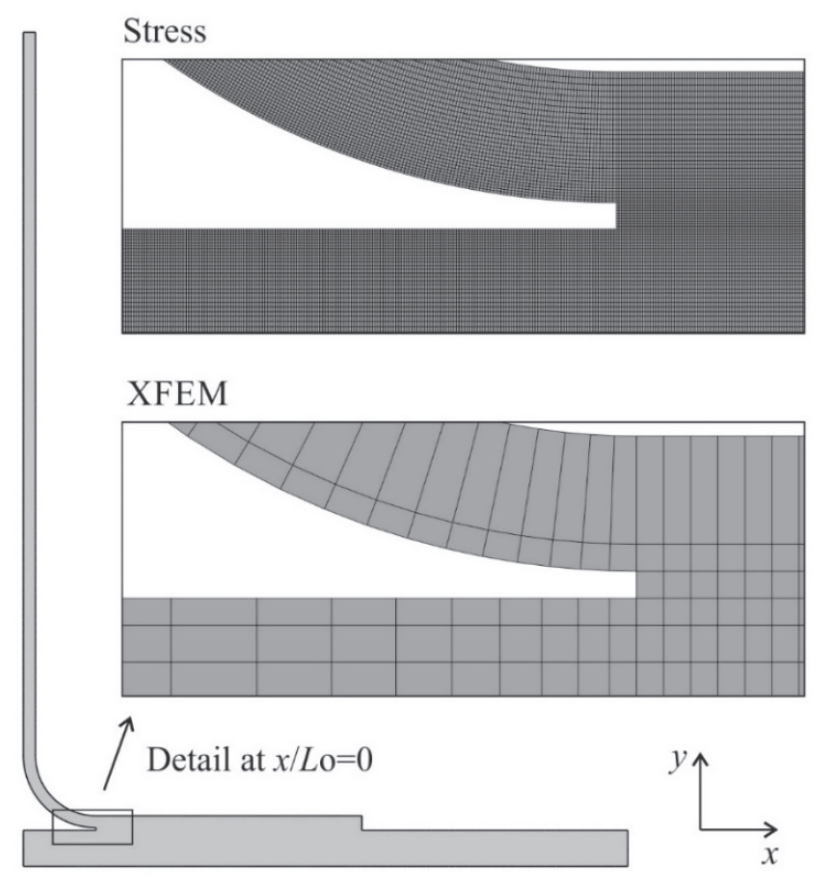

Figure 3: Mesh details at $x / L_{0}=0$ for the joint with $t_{P 2}=1 \mathrm{~mm}$ : stress analysis and XFEM strength prediction analyses. 
Mesh bias effects were employed in the models to grade the elements' size, enabling to reduce the total number of elements but without compromising the accuracy. This was done by considering a more refined mesh near the adhesive layer and towards its edges, and a coarser mesh in the zones with less stress variations [28]. The elements' side dimensions in the adhesive layer for the XFEM simulations were $0.2 \times 0.2 \mathrm{~mm}$ along the bondline, i.e., only one element through-thickness was considered. On the other hand, the models for the stress analysis were comprised of $0.02 \times 0.02 \mathrm{~mm}$ elements at the overlap edges. The boundary conditions consisted of fixing the base edges to simulate gripping in the testing machine, applying symmetry at the middle of the specimen and pulling the curved adherends' edges in peel.

\section{XFEM formulation}

As an extension to the conventional FEM, the XFEM is based on the integration of enrichment functions in the FEM formulation [29]. These functions allow modelling the displacement jump between crack faces that occur during the propagation of a crack. The Abaqus ${ }^{\circledR}$ XFEM formulation enables the user to create a pre-crack, or it can initiate cracks in un-cracked regions by using initiation criteria. In this last scenario, considered in this work, damage initiates and subsequently propagates during the simulation at regions experiencing stresses and/or strains higher than the corresponding limiting values. Six crack initiation criteria are available in Abaqus ${ }^{\circledR}$. The MAXPS (maximum principal stress) and MAXPE (maximum principal strain) criteria are based on the introduction of the following functions (by the respective order)

$$
f=\left\{\frac{\left\langle\sigma_{\max }\right\rangle}{\sigma_{\max }^{0}}\right\} \quad \text { or } \quad f=\left\{\frac{\left\langle\varepsilon_{\max }\right\rangle}{\varepsilon_{\max }^{0}}\right\}
$$

$\sigma_{\max }$ and $\sigma_{\max }$ represent the current and allowable maximum principal stress. The Macaulay brackets indicate that a purely compressive stress state does not induce damage. $\varepsilon_{\max }$ and $\varepsilon^{0} \max$ represent the current and allowable maximum principal strain. Crack growth for the MAXPS and MAXPE criteria is software defined as orthogonal to the maximum principal stress/strain direction. As a result of this, and due to the inherent mixed-mode loading of these joints, the crack grows fast towards the adherends. For these two criteria, the maximum load $\left(P_{\mathrm{m}}\right)$ estimation was thus considered to take place at the time of first cracking in the adhesive layer. The MAXS (maximum nominal stress) and MAXE (maximum nominal strain) criteria are represented by the following functions, respectively

$$
f=\max \left\{\frac{\left\langle t_{\mathrm{n}}\right\rangle}{t_{\mathrm{n}}^{0}}, \frac{t_{\mathrm{s}}}{t_{\mathrm{s}}^{0}}\right\} \quad \text { or } \quad f=\max \left\{\frac{\left\langle\varepsilon_{\mathrm{n}}\right\rangle}{\varepsilon_{\mathrm{n}}^{0}}, \frac{\varepsilon_{\mathrm{s}}}{\varepsilon_{\mathrm{s}}^{0}}\right\}
$$

$t_{\mathrm{n}}$ and $t_{\mathrm{s}}$ are the current normal and shear traction components to the cracked surface. $t_{\mathrm{n}}{ }^{0}$ and $t_{\mathrm{s}}{ }^{0}$ represent the respective limiting values. The strain parameters have identical significance. The quadratic nominal stress (QUADS) and quadratic nominal strain (QUADE) criteria are based on the introduction of the following functions, respectively

$$
f=\left\{\frac{\left\langle t_{\mathrm{n}}\right\rangle}{t_{\mathrm{n}}^{0}}\right\}^{2}+\left\{\frac{t_{\mathrm{s}}}{t_{\mathrm{s}}^{0}}\right\}^{2} \quad \text { or } \quad f=\left\{\frac{\left\langle\varepsilon_{\mathrm{n}}\right\rangle}{\varepsilon_{\mathrm{n}}^{0}}\right\}^{2}+\left\{\frac{\varepsilon_{\mathrm{s}}}{\varepsilon_{\mathrm{s}}^{0}}\right\}^{2}
$$

For the MAXS, MAXE, QUADS and QUADE criteria the user can select between horizontal or vertical crack growth (in this work horizontal growth, i.e., along the adhesive layers' length, was selected). All the six aforementioned criteria are fulfilled, and damage initiates, when $f$ reaches unity. For damage growth, the fundamental expression of the displacement vector $\mathbf{u}$, including the displacements enrichment, is written as [30]

$$
\mathbf{u}=\sum_{i=1}^{N} N_{i}(x)\left[\mathbf{u}_{i}+H(x) \mathbf{a}_{i}\right]
$$

$N_{i}(x)$ and $\mathbf{u}_{i}$ relate to the conventional FEM formulation, corresponding to the nodal shape functions and nodal displacement vector linked to the continuous part of the formulation, respectively. The second term between brackets, $H(x) \mathbf{a}_{i}$, is only active in the nodes for which any relating shape function is cut by the crack and can be expressed by the product of the nodal enriched degree of freedom vector including the mentioned nodes, $\mathbf{a}_{i}$, with the associated 
discontinuous shape function, $H(x)$, across the crack surfaces. The method is based on the establishment of phantom nodes that subdivide elements cut by a crack and simulate separation between the newly created sub-elements. Propagation of a crack along an arbitrary path is made possible by the use of these phantom nodes that initially have exactly the same coordinates than the real nodes and that are completely constrained to the real nodes up to damage initiation. After being crossed by a crack, the element is partitioned in two sub-domains. The discontinuity in the displacements is made possible by adding phantom nodes superimposed to the original nodes. When an element cracks, each one of the two sub-elements will be formed by real nodes (the ones corresponding to the cracked part) and phantom nodes (the ones that no longer belong to the respective part of the original element). These two elements that have fully independent displacement fields replace the original one. Thus, the crack size increment for a given crack orientation is equal to the distance between the cracked element's edges. From this point, each pair of real/phantom node of the cracked element is allowed to separate according to a suitable damage law up to failure. At this stage, the real and phantom nodes are free to move unconstrained, simulating crack growth. Tab. 2 summarizes the parameters introduced in Abaqus $^{\circledR}$. A linear softening XFEM law was initially considered with an energetic failure power law criterion of the type

$$
\left(\frac{G_{\mathrm{I}}}{G_{\mathrm{IC}}}\right)^{\alpha}+\left(\frac{G_{\mathrm{II}}}{G_{\mathrm{IIC}}}\right)^{\alpha}=1,
$$

in which $\alpha$ is the damage law exponent ( $\alpha=1$ for linear softening).

\begin{tabular}{|c|c|c|c|}
\hline Property & AV138 & 2015 & 7752 \\
\hline$E$ [GPa] & 4.89 & 1.85 & 0.49 \\
\hline$G$ [GPa] & 1.81 & 0.70 & 0.19 \\
\hline$\sigma_{\max }[\mathrm{MPa}]$ & 39.45 & 21.63 & 11.48 \\
\hline$\varepsilon_{\max }^{0}[\%]$ & 1.21 & 4.77 & 19.18 \\
\hline$t_{\mathrm{n}}^{0}[\mathrm{MPa}]$ & 39.45 & 21.63 & 11.48 \\
\hline$t_{\mathrm{s}}^{0}[\mathrm{MPa}]$ & 30.2 & 17.9 & 10.17 \\
\hline$\varepsilon_{\mathrm{n}}^{0}[\%]$ & 1.21 & 4.77 & 19.18 \\
\hline $\mathcal{E}_{\mathrm{s}}^{0}[\%]$ & 7.8 & 43.9 & 54.82 \\
\hline$G_{\text {IC }}[\mathrm{N} / \mathrm{mm}]$ & 0.20 & 0.43 & 2.36 \\
\hline$G_{\text {IIC }}[\mathrm{N} / \mathrm{mm}]$ & 0.38 & 4.70 & 5.41 \\
\hline
\end{tabular}

Table 2: Parameters of the Araldite ${ }^{\circledR}$ AV138, Araldite ${ }^{\circledR} 2015$ and Sikaforce ${ }^{\circledR} 7752$ for XFEM modelling.

\section{RESULTS}

\section{Experimental failure modes}

11 failures took place beginning with crack propagation at $x / L_{0}=0$ and growing towards the other edge. After failure, the fracture surfaces were inspected and cohesive failures were found for all adhesives and tp2. However, in some 1 cases, especially for the joints bonded with the Araldite ${ }^{\circledR}$ AV138, failure sometimes took place near to one of the adherend/adhesive interfaces (Fig. 4 shows an example for the joints with $t_{2}=2 \mathrm{~mm}$ ), such that visually it resembled an adhesive failure. However, careful surface inspection including optical microscope observations revealed that the adherends that at first hand suffered form an adhesive failure actually were covered by a thin layer of adhesive. These findings are consistent with previous observations on this particular adhesive [27]. The fracture surfaces for the joints bonded with the Araldite $^{\circledR} 2015$ and Sikaforce ${ }^{\circledR} 7752$ were smoother, indicative of ductile fractures, with a clearer evidence of cohesive failures. L-part adherend plasticization was detected in all joints bonded with the Araldite ${ }^{\circledR} 2015$ and $t_{\mathrm{p} 2}=1 \mathrm{~mm}$, and also with the Sikaforce ${ }^{\circledR} 7752$ and $t_{2}=1$ and $2 \mathrm{~mm}$, although for this last case it was under $0.1 \%$. 


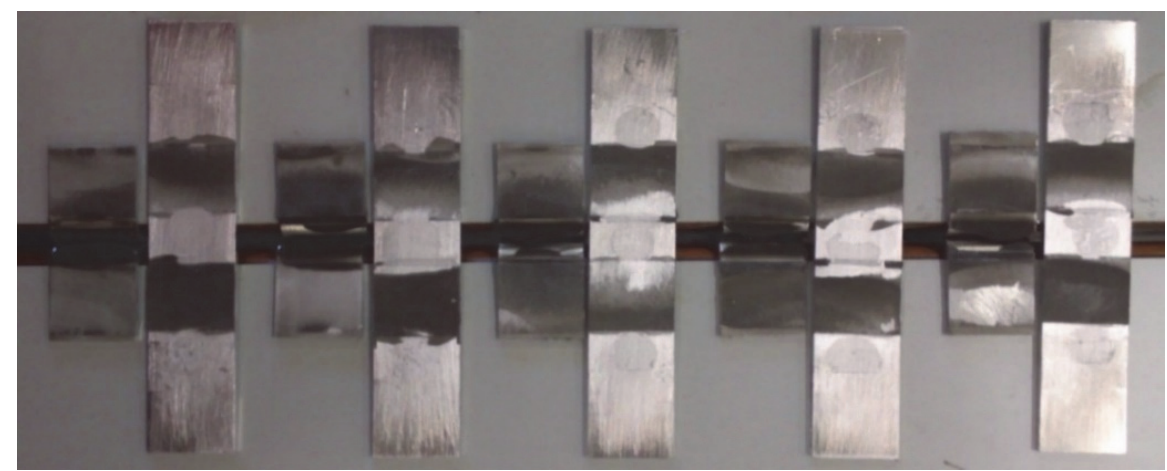

Figure 4: Fracture surfaces for the five sets of T-joints bonded with the Araldite ${ }^{\circledR}$ AV138 and with $t_{\mathrm{P} 2}=2 \mathrm{~mm}$ (for each set the $L$-parts are at the left and the base adherend to the right).

\section{Stresses in the elastic domain}

This Section briefly evaluates $\sigma_{\mathrm{y}}$ and $\tau_{\mathrm{xy}}$ stresses along the adhesive during the initial stages of the elastic loading, such that the differences between adhesives and tp2 are properly accounted for. The graphics are represented as follows:

- The $x$-axis represents the normalized distance along the adhesive length $\left(x / L_{0}\right)$, in which $x$ is the horizontal coordinate beginning at the leftmost edge of the adhesive layer, i.e. the edge closest to the central portion of the joint;

- The $y$-axis represents the normalized $\sigma_{\mathrm{y}}$ and $\tau_{\mathrm{xy}}$ stresses $\left(\sigma_{\mathrm{y}} / \sigma_{\mathrm{avg}}\right.$ and $\tau_{\mathrm{xy}} / \sigma_{\text {avg }}$, respectively). $\sigma_{\mathrm{avg}}$ is the average $\sigma_{\mathrm{xy}}$ stress along the adhesive mid-thickness for the respective tp2.

Between the three adhesives, stresses in the elastic loading stage are identical, with the sole difference residing in the normalized peak values, since these increase in proportion with the adhesive stiffness ( $E$ values compared in Tab. 1) [31]. Thus, graphically, only the results for one adhesive are presented, in this case for the Aradite ${ }^{\circledR} 2015$ (Fig. 5), which has the middle stiffness. It can be first observed that $\sigma_{\mathrm{y}}$ stresses are prevalent over $\tau_{\mathrm{xy}}$ stresses, which was expected due to the expected peel loading, although $\tau_{\mathrm{xy}}$ of non-negligible magnitude also develop due to the sliding of the L-part over the base adherend. Independently of $t_{\mathrm{P} 2}$, peak stresses or at least stress perturbations exist at the vicinity of $x / L_{\mathrm{O}}=0 \mathrm{and} 1 \mathrm{~mm}$, which consist of the stress singularity regions.
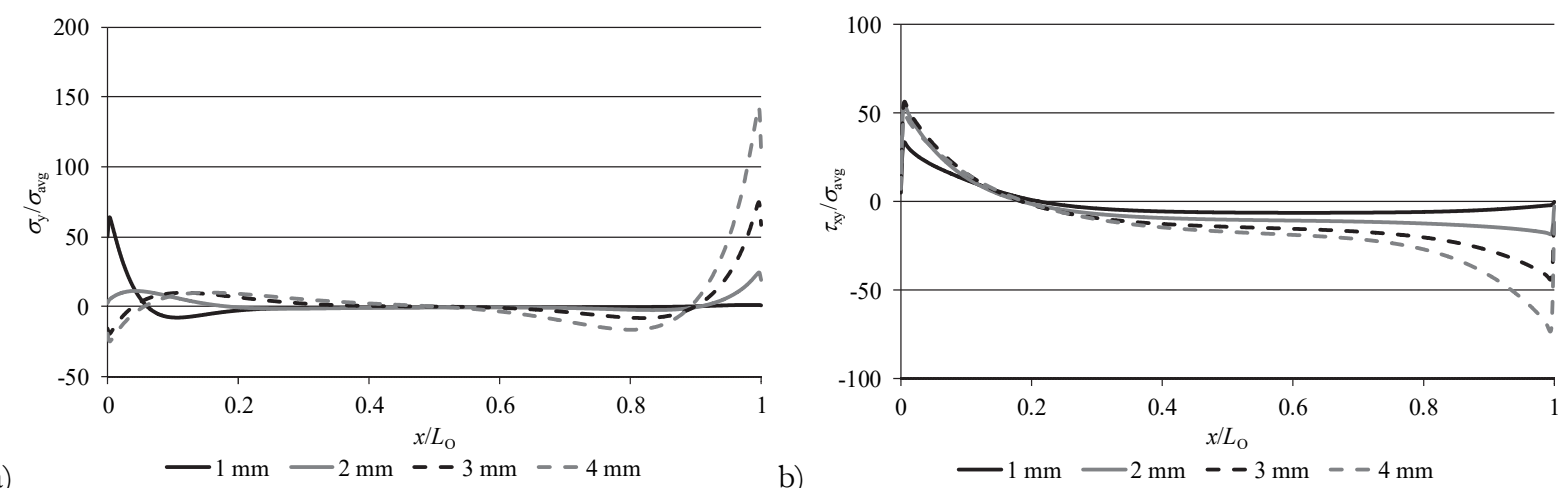

Figure 5: Normalized $\sigma_{\mathrm{y}}(\mathrm{a})$ and $\tau_{\mathrm{xy}}$ (b) stresses along the adhesive mid-thickness for the T-joints bonded with the Araldite ${ }^{\circledR} 2015$.

$\sigma_{\mathrm{y}}$ stresses were identical between the three adhesives, although with the aforementioned differences in magnitude of peak stresses. The curves depicted in Fig. 5 (a), relating to the Araldite ${ }^{\circledR}$ 2015, showed intermediate peak values between the other two adhesives. For the joints with $t_{2}=1 \mathrm{~mm}$, the critical region was undoubtedly $x / L_{0}=0$, due to the small stiffness of the L-part, arising from its low thickness. For the other $t_{\mathrm{p} 2}, \sigma_{\mathrm{y}}$ stresses are either close to zero or compressive at this location. The increase of $t_{\mathrm{P} 2}$ gradually reduces the harmful effect of $\sigma_{\mathrm{y}}$ peak stresses at $x / L_{\mathrm{O}}=0$, but gradually loads the other edge $\left(x / L_{0}=1\right)$, which is deemed to occur because of the growing thickness and stiffness of the L-part. Actually, this change in deformation pattern of the L-part, namely the significant reduction of its bending, works against the natural curvature 
developing in the straight adherend due to the tensile pulling. This gives rise to tensile $\sigma_{\mathrm{y}}$ peak stresses near $x / L_{\mathrm{O}}=1$, while the other edge tends to become lightly loaded. This effect can even be responsible by an alteration of the failure path if $t_{\mathrm{p} 2}$ reaches a given limit. On the other hand, $\sigma_{\mathrm{y}}$ stresses tend to span for a bigger region of the bonding length with the increase of $t_{\mathrm{p} 2}$, which can be responsible for a $P_{\mathrm{m}}$ improvement.

Identically to that found for $\sigma_{\mathrm{y}}$ stresses, the behaviour of $\tau_{\mathrm{xy}}$ stresses has large similarities between adhesives, although with peak magnitude variation between adhesives due to their stiffness differences. The T-joints bonded with the Araldite ${ }^{\circledR} 2015$, whose curves are shown in Fig. 5 (b), presented a middle behaviour between the three tested adhesives. The smallest $\tau_{\mathrm{xy}}$ peak stresses are those of the joints with $t_{\mathrm{p} 2}=1 \mathrm{~mm}$ and, for this joint, $\tau_{\mathrm{xy}}$ stresses peak close to $x / L_{0}=0$, while being negligible for the remainder of the bonding portion. On the other hand, the increase of $t_{\mathrm{p} 2}$ lightly increases $\tau_{\mathrm{xy}}$ peak stresses near $x / L_{\mathrm{O}}=0$, concurrently with a progressive increase of $\tau_{\mathrm{xy}}$ peak stresses near $x / L_{\mathrm{O}}=1$. This modification in the $\tau_{\mathrm{xy}}$ stress plots is related to the aforementioned behaviour of $\sigma_{\mathrm{y}}$ stresses, i.e., due to the stiffening effect of the L-part, which is not accompanied by the transverse deformation of the base adherend, which subsequently leads to large adhesive strains near $x / L_{\mathrm{O}}=1$. Moreover, the variation of $\tau_{\mathrm{xy}}$ stress plots can also influence the failure onset and growth, identically for that discussed for $\sigma_{\mathrm{y}}$ stresses.

\section{Study of the SDEG (damage) variable}

The stiffness degradation (SDEG variable) of the XFEM damage laws along the bonded length is addressed in this Section, with the objective of describing the extent of damage along the adhesive at the $P_{\mathrm{m}}$ of the joints. The SDEG variable ranges from 0 to 1 , in which 0 represents the absence of damage, i.e., the respective set of nodes are within the elastic loading phase, and 1 corresponds to full separation. SDEG values in-between indicate that the set of nodes is in the stress softening phase. Fig. 6 shows the SDEG plots at $P_{\mathrm{m}}$ along $x / L_{0}$ for the T-joints bonded with the Araldite ${ }^{\circledR}$ AV138 (a), Araldite ${ }^{\circledR} 2015$ (b) and Sikaforce ${ }^{\circledR} 7752$ (c). For each adhesive, the four joint geometries are analysed $\left(t_{\mathrm{p} 2}=1,2,3\right.$ and $\left.4 \mathrm{~mm}\right)$.

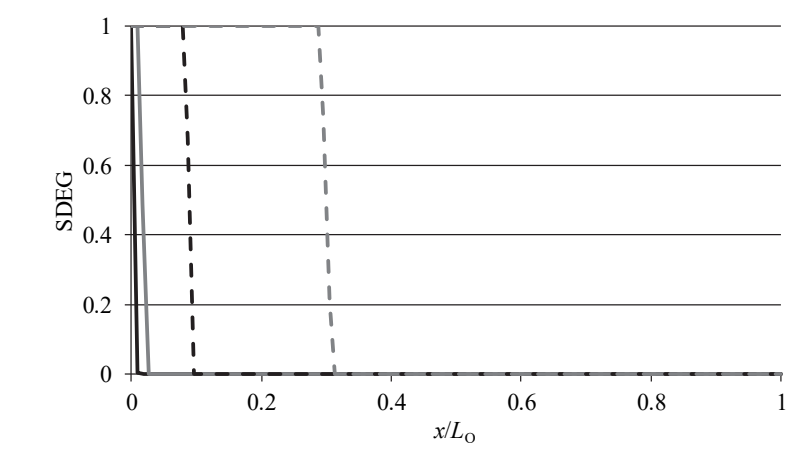

a)
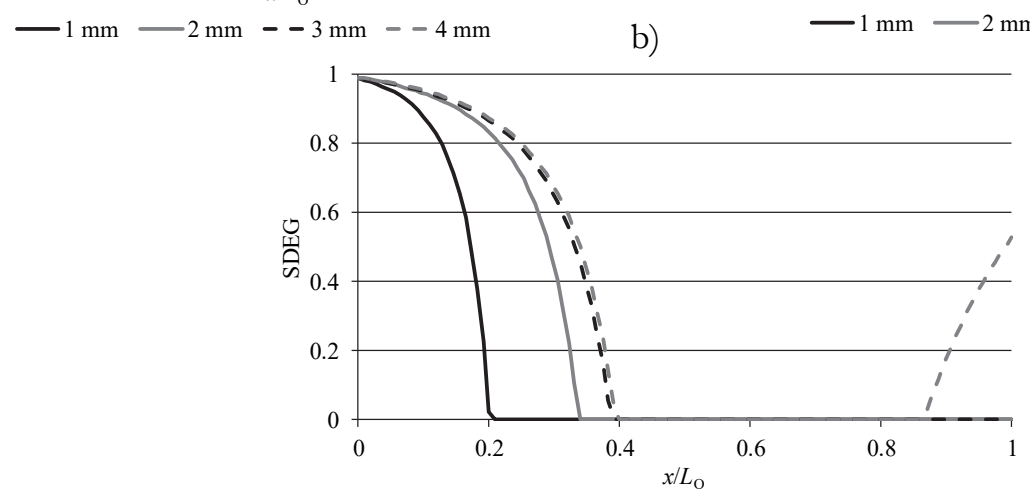

c)

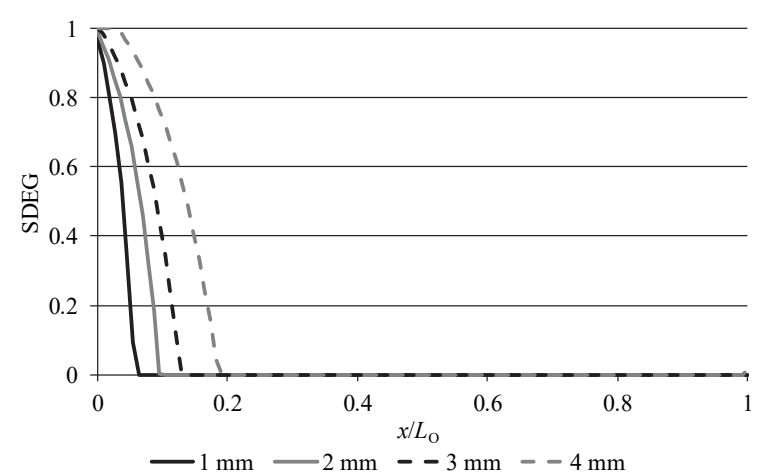

b)

$-1 \mathrm{~mm}-2 \mathrm{~mm}--3 \mathrm{~mm}--4 \mathrm{~mm}$

Figure 6: SDEG variable at the $P_{\mathrm{m}}$ instant for the T-joints bonded with the Araldite ${ }^{\circledR}$ AV138 (a), Araldite ${ }^{\circledR} 2015$ (b) and Sikaforce ${ }^{\circledR} 7752$ (c).

The comparison between the three adhesives clearly shows different behaviours. The brittleness of the Araldite ${ }^{\circledR}$ AV138 reflects on a much localised portion of the adhesive layer under damage at the time $P_{\mathrm{m}}$ is reached in the T-joints. This is visible by the steepness of the SDEG plot between SDEG=1 and 0. Moreover, at $P_{\mathrm{m}}$ some portion of the adhesive layer is already fully damaged, especially for bigger te2. This could be indicative of brittle failure and a lesser performance of this 
adhesive in the $\mathrm{T}$-joint configuration. The damage evolution is more gradual for the other adhesives, due to their inherent ductility, especially for the Sikaforce ${ }^{\circledR} 7752$. For the Araldite ${ }^{\circledR} 2015$, despite this modification in the failure process, it is clear that a damaged portion of adhesive of non-negligible dimensions is present which, in this particular loading case, can prove to have a positive effect on $P_{\mathrm{m}}$. This ductility effect is even more visible in the Sikaforce ${ }^{\circledR} 7752$. Inclusively, for $t_{\mathrm{P} 2}=4 \mathrm{~mm}$, a portion of adhesive in the vicinity of $x / L_{0}=1$ also undergoes damage. For all adhesives, a modification of the SDEG and a clear tendency are found depending on tor. Irrespectively of the adhesive, the damage tends to extend further with the increase of t.22. At $P_{\mathrm{m}}$, the portion of adhesive under damage (SDEG between 0 and 1 ) for the Araldite ${ }^{\circledR}$ AV138 is 1.8; 2.6; 9.5 and $31.3 \%$ for $t_{2}=1,2,3$ and $4 \mathrm{~mm}$, respectively. By the same sequence, these percentile values increase to $6.3 ; 9.5 ; 13.0$ and $19.1 \%$ for the Araldite ${ }^{\circledR} 2015$ and further to $20.9 ; 33.9 ; 39.1$ and $40.0 \%$ for the Sikaforce ${ }^{\circledR} 7752$. This evolution between adhesives is clearly due to the increasing ductility of the adhesives in the mentioned order, depicted in Tab. 1 through the values of $G_{\text {IC }}$ and $G_{\text {IIC. }}$ Moreover, $\sigma_{\mathrm{y}}$ and $\tau_{\text {xy }}$ peak stresses reduce from the Araldite ${ }^{\circledR}$ AV138 to the Araldite ${ }^{\circledR} 2015$, and even further to the Sikaforce ${ }^{\circledR} 7752$, due to the differences in elastic stiffness (Tab. 1), which helps in spreading the damage across the adhesive layer. Higher damage zones should help in attaining higher $P_{\mathrm{m}}$ in this particular joint configuration, which traditionally concentrates the load in a small portion of the adhesive. On the other hand, irrespectively of the adhesive, its damaged portion always increases with $t_{\mathrm{p} 2}$, which can be explained by the corresponding reduction of L-part deformations due to a load scenario that gradually shifts from peeling to cleavage as to 2 increases. This shift should also bring a higher joint efficiency, because the adhesive region resisting pull-out increases.

\section{Experimental strength}

The experimentally obtained $P_{\mathrm{m}}$ for the T-joints bonded with the three adhesives are presented in this Section. Fig. 7 reports the average $P_{\mathrm{m}}$ vs. t. 2 curves, including the standard deviation of the experiments.

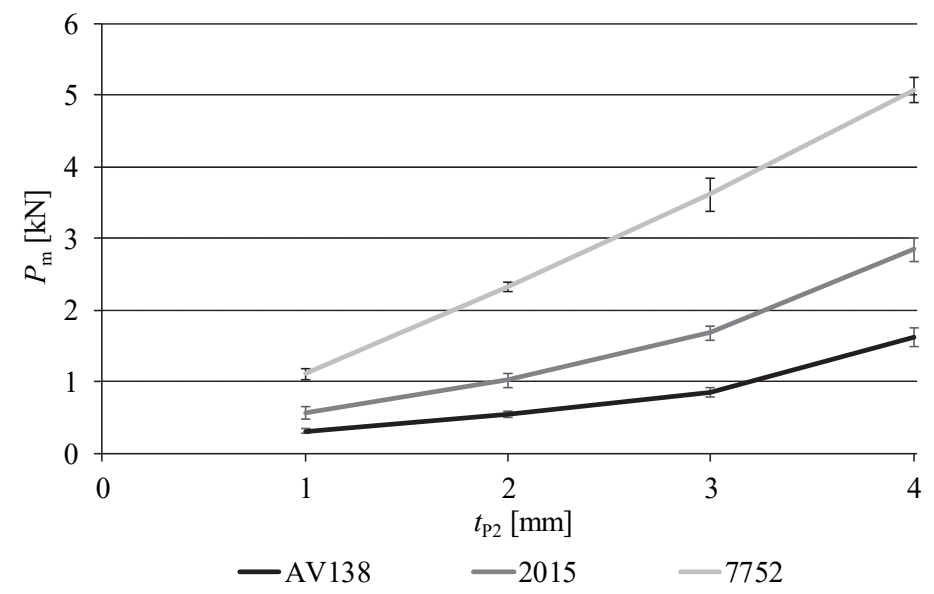

Figure 7: Experimental $P_{\mathrm{m}}$ vs. $t_{\mathrm{p} 2}$ curves for the three adhesives.

It can be found that $P_{\mathrm{m}}$ always increases, and by a large amount, with $t_{\mathrm{p} 2}$, irrespectively of the adhesive. The two Araldite ${ }^{\circledR}$ adhesives show an increasing growth with $t_{\mathrm{p} 2}$, while the Sikaforce ${ }^{\circledR} 7752$ has a marked linear evolution of the $P_{\mathrm{m}}$ vs. $t_{\mathrm{p} 2}$ curve. The percentile $P_{\mathrm{m}}$ increase for the T-joints with $t_{\mathrm{p} 2}=2,3$ and $4 \mathrm{~mm}$, over the T-joint with $t_{\mathrm{p} 2}=1 \mathrm{~mm}$, was respectively of $75.0 \%, 173.8 \%$ and $419.3 \%$ (Araldite ${ }^{\circledR}$ AV138), 81.2\%, 197.8\% and 403.7\% (Araldite ${ }^{\circledR} 2015$ ) and $110.9 \%, 227.1 \%$ and $358.6 \%$ (Sikaforce ${ }^{\circledR} 7752$ ). This marked $P_{\mathrm{m}}$ improvement with $t_{\mathrm{p} 2}$ is mainly due to the $\sigma_{\mathrm{y}}$ stress levelling effect that is visible in Fig. 5 (a) near $x / L_{0}=0$, which corresponds to the stress initiation site. Subsequently, this also reflects in a more widespread damage span (i.e., $0<$ SDEG $<1$ ) with the increase of $t_{22}$, as it is visible in Fig. 6 for the three adhesives, although more clearly for the Araldite ${ }^{\circledR} 2015$ and Sikaforce ${ }^{\circledR}$ 7752. Between adhesives, the Sikaforce ${ }^{\circledR} 7752$ clearly outperforms the other two adhesives, despite being the less strong amongst the three adhesives (Tab. 1). The $P_{\mathrm{m}}$ improvement of the T-joints bonded with this adhesive, over those bonded with the Araldite ${ }^{\circledR}$ AV138, ranges between $213.8 \%\left(t_{\mathrm{p} 2}=4 \mathrm{~mm}\right)$ and $328.0 \%\left(t_{\mathrm{p} 2}=2\right.$ $\mathrm{mm}$ ). On the other hand, compared against the joints bonded with the Araldite ${ }^{\circledR} 2015$, the $P_{\mathrm{m}}$ improvement varies between $78.5 \%\left(t_{\mathrm{p} 2}=4 \mathrm{~mm}\right)$ and $128.1 \%$ (t $t_{\mathrm{P} 2}=2 \mathrm{~mm}$ ). It is also visible in Fig. 7 that $P_{\mathrm{m}}$ for the joints bonded with the Araldite ${ }^{\circledR} 2015$ are higher than those with the Araldite ${ }^{\circledR}$ AV138. In fact, depending on $t_{\mathrm{p} 2}, P_{\mathrm{m}}$ may almost double that obtained with the Araldite ${ }^{\circledR}$ AV138 adhesive, although this adhesive has higher strengths. The improvement is minimum for $t_{2} 2=4 \mathrm{~mm}(78.4 \%)$ and maximum for $t_{\mathrm{p} 2}=3 \mathrm{~mm}(97.2 \%)$. These results show that, in a test geometry that is mainly loaded in peel, and which 
promotes stresses to be concentrated in small areas, flexible and ductile adhesives behave best. In one hand, the flexibility tends to increase the area along which stresses are being transferred (Fig. 5). On the other hand, the ductility permits plasticization of the adhesive at the stress concentration sites while the regions in the vicinity becomes loaded, resulting in an overall improved behaviour.

\section{Numerical evaluation of the XFEM initiation criterion}

The XFEM initiation criteria described in Section "XFEM formulation" are evaluated against the experimental data, by directly comparing $P_{\mathrm{m}}$ with the experiments. At this stage, the linear energetic criterion, considering $\alpha=1$ in Eqn. (5), is considered in all simulations. As it was previously discussed, the use of the MAXS, MAXE, QUADS and QUADE criteria results in crack onset and growth parallel to the adhesive layer, while MAXPS and MAXPE criteria leads to cracking perpendicular to the maximum principal stresses or strains, which subsequently makes the crack grow in the direction of the adherends. Fig. 8 shows the $P_{\mathrm{m}}$ comparison for all tp2 between the different XFEM initiation criteria and the experiments for the adhesives Araldite ${ }^{\circledR}$ AV138 (a), Araldite ${ }^{\circledR} 2015$ (b) and Sikaforce ${ }^{\circledR} 7752$ (c).

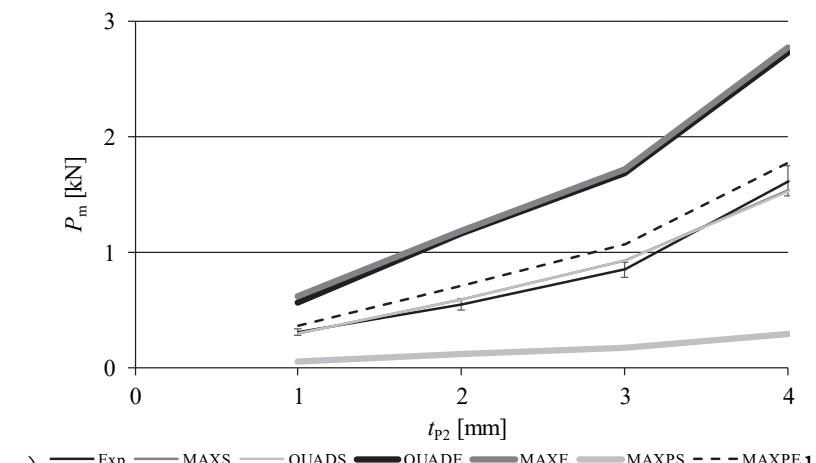

a)

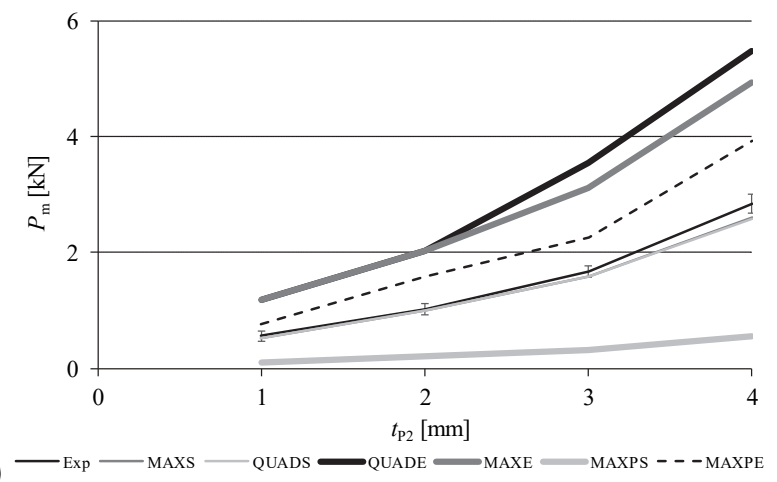

b)

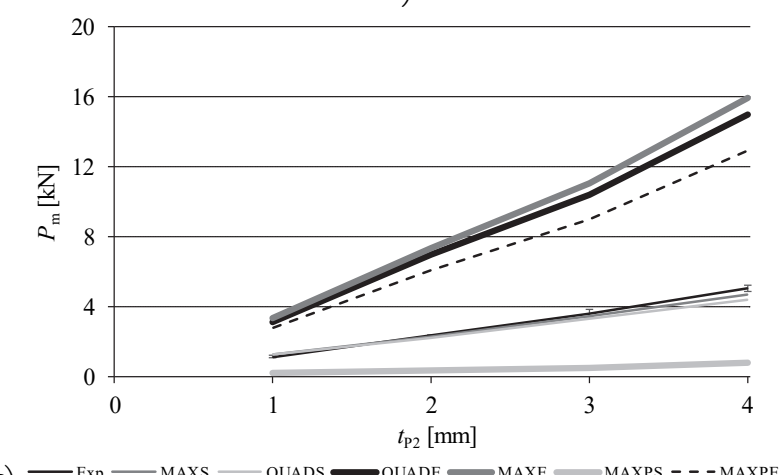

c) — Exp — Maxs — QUADS — QUADE — MAXE —MAXPs - - MAXPe

Figure 8: Experimental and numerical $P_{\mathrm{m}}$ comparison, considering different XFEM initiation criteria, for the T-joints bonded with the Araldite $^{\circledR}$ AV138 (a), Araldite $^{\circledR} 2015$ (b) and Sikaforce ${ }^{\circledR} 7752$ (c).

For the Araldite ${ }^{\circledR}$ AV138, the QUADS and MAXS criteria are closest to the experimental points, and the respective curves are practically overlapped in the figure. Averaged over the experiments, the maximum relative deviations were $+8.8 \%\left(t_{\mathrm{p}}=2\right.$ $\mathrm{mm})$ and $+9.5 \%\left(t_{\mathrm{p} 2}=2 \mathrm{~mm}\right)$, respectively, for these two criteria. The MAXPS criterion revealed to be unsuited, in the manner that it was used, since $P_{\mathrm{m}}$ highly underestimates the tests (up to $-82.5 \%$ for $t_{\mathrm{p} 2}=1 \mathrm{~mm}$ ). Oppositely to this behaviour, the strain-based criteria (QUADE, MAXE and MAXPE) overshoot the experimental data, with emphasis to the QUADE and MAXE. The highest offsets for these criteria were $+113.3 \%$ (QUADE), $+117.3 \%$ (MAXE) and $+31.3 \%$ (MAXPE), in all cases for $t_{\mathrm{p} 2}=2 \mathrm{~mm}$. Qualitatively, the $P_{\mathrm{m}}$ predictions for the Araldite ${ }^{\circledR} 2015$ by the six criteria agree with those of the Araldite ${ }^{\circledR}$ AV138. Thus, the QUADS and MAXS criteria are quite close to the experimental values, with a negligible difference between them. The maximum $P_{\mathrm{m}}$ deviations were, in both cases, obtained for $t_{\mathrm{P} 2}=4 \mathrm{~mm}$, attaining $-8.9 \%$ (QUADS) and -8.6\% (MAXS). The MAXPS criterion was offset up to $-81.3 \%\left(t_{\mathrm{p} 2}=1 \mathrm{~mm}\right)$, whilst the maximum deviations for the strain-based criteria attained maximums of $+110.7 \%$ for both QUADE and MAXE (tp2 $=1 \mathrm{~mm}$ ), and $+55.2 \%$ the MAXPE criterion $\left(t_{2}=2 \mathrm{~mm}\right)$. Finally, the results for the Sikaforce ${ }^{\circledR} 7752$ were much alike those of the former adhesives although, in this case, even the QUADS and MAXS criteria showed bigger variations to the experimental $P_{\mathrm{m}}$ (up to $-13.3 \%$ 
for the QUADS, considering $t_{\mathrm{p} 2}=4 \mathrm{~mm}$, and $+13.3 \%$ for the MAXS, considering $t_{\mathrm{p} 2}=1 \mathrm{~mm}$ ). Identically, the curves for these two criteria overlap. Due to the aforementioned approximations, the MAXPS criterion showed $P_{\mathrm{m}}$ values much below the expected, with a maximum deviation of $-85.8 \%\left(t_{\mathrm{p} 2}=3 \mathrm{~mm}\right)$. The strain-based criteria significantly over predicted $P_{\mathrm{m}}$, in line with the previous adhesives. The maximum offsets, all by excess, were $+197.8 \%$ for the QUADE $\left(t_{\mathrm{p} 2}=2 \mathrm{~mm}\right),+214.7 \%$ for the MAXE $\left(t_{\mathrm{p} 2}=4 \mathrm{~mm}\right)$ and $+160.5 \%$ for the MAXPE $\left(t_{\mathrm{p} 2}=2 \mathrm{~mm}\right)$.

It was shown in a previous work [23] that damage initiation is ruled by the adhesive layer's stresses rather than the strains (which also vary by a large amount between adhesives). On the other hand, using strain-based criteria can result in major deviations to the real joint behaviour, with an over prediction tendency. This is why the QUADS and MAXS criteria generally work very well. The QUADE and MAXE criteria, being based on strains, naturally present wrong $P_{\mathrm{m}}$ results and should not be considered in the design process of bonded joints. The MAXPS and MAXPE criteria, due to its intrinsic formulation, are unable to promote a realistic damage growth path, since the crack growth direction is ruled by the maximum principal stresses or strains, in a sense that crack initiates and grows perpendicularly to the principal directions. As a result, adherend detaching by the adhesive through all the adhesive layer is rendered unfeasible because the mixed-mode loading induced in the adhesive results in short crack growth in the adhesive before the crack hits the adherend interface. Since $P_{\mathrm{m}}$ was assessed by the damage initiation load, i.e., at the time the first crack appears in the model, the results do not match the real joint behaviour. Moreover, since stresses and strains in FEM modelling are traditionally mesh dependent [11], the direct use of initiation criteria to assess failure, i.e., without failure criteria, should promote mesh-dependent $P_{\mathrm{m}}$.

\section{Numerical evaluation of the XFEM propagation criterion}

The study of the propagation criterion relied on the use of the QUADS initiation criterion, due to the consistency of results shown in the previous Section, and consisted of changing the mixed-mode exponent $\alpha$ in expression (5) using the linear damage law, by considering $\alpha=0.5,1$ and 2, and also testing an exponential damage law with $\alpha=1$. Usually, from reported data [32], the triangular law manages to represent with accuracy the behaviour of the adhesive layer, but changing this parameter leads to different mixed-mode conditions for element failure, which may or not prove to have a noteworthy influence on the results. Fig. 9 depicts the experimental and numerical $P_{\mathrm{m}}$ comparison under the mentioned modelling conditions, for the T-joints bonded with the Araldite ${ }^{\circledR}$ AV138 (a), Araldite ${ }^{\circledR} 2015$ (b) and Sikaforce ${ }^{\circledR} 7752$ (c).
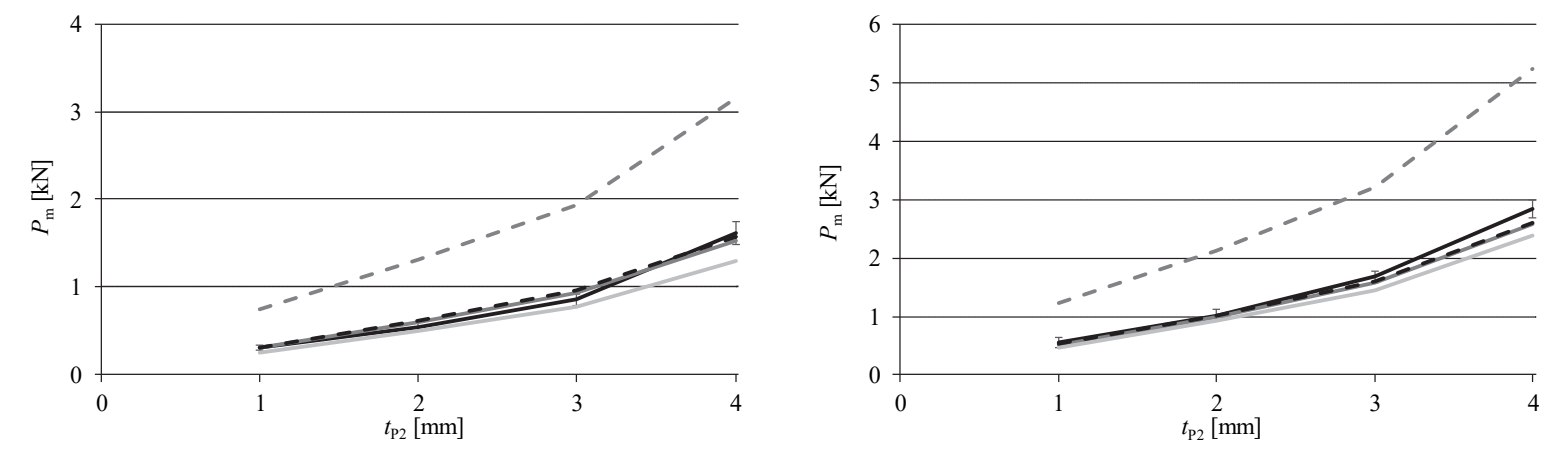

a)

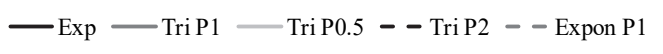

b)
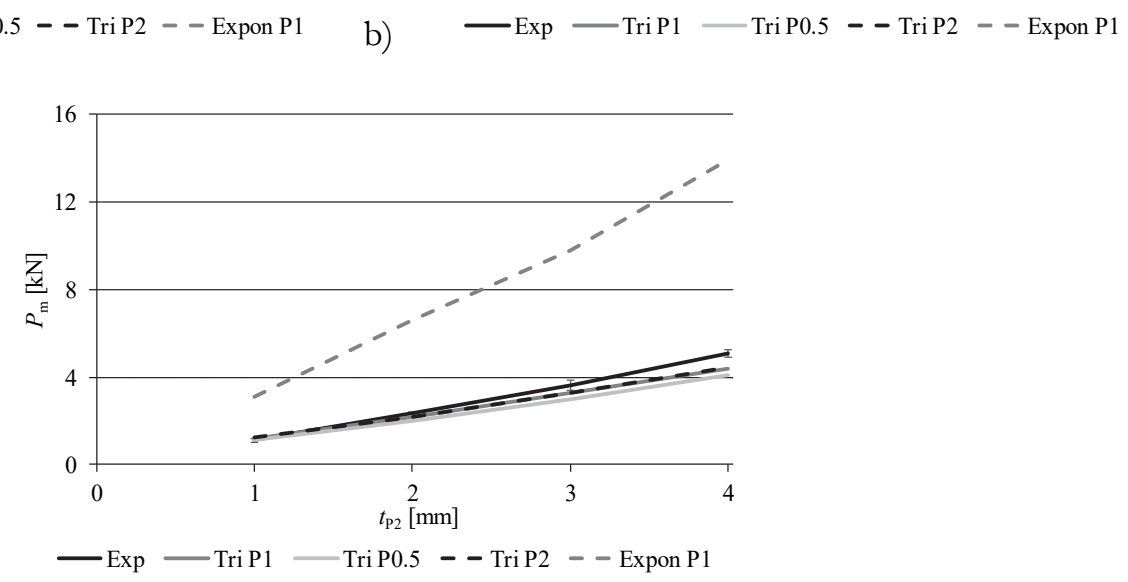

Figure 9: Experimental and numerical $P_{\mathrm{m}}$ comparison, considering different XFEM propagation models, for the T-joints bonded with the Araldite ${ }^{\circledR}$ AV138 (a), Araldite ${ }^{\circledR} 2015$ (b) and Sikaforce ${ }^{\circledR} 7752$ (c). 
In the case of joints bonded with the Araldite ${ }^{\circledR}$ AV138, the triangular propagation law with $\alpha=1$ presents the closest values to the experiments. Compared against the test results, the relative deviations for these conditions ranged between $-4.1 \%$ $\left(t_{\mathrm{P} 2}=1 \mathrm{~mm}\right)$ and $+8.8 \%\left(t_{\mathrm{P} 2}=2 \mathrm{~mm}\right)$. The results were much similar for $\alpha=2$, with a maximum deviation for $t_{\mathrm{P} 2}=3 \mathrm{~mm}$ of $+12.5 \%$. On the hand, $\alpha=0.5$ led to under predicted $P_{\mathrm{m}}$, up to $-21.6 \%\left(t_{\mathrm{p} 2}=1 \mathrm{~mm}\right)$. The exponential law proved to be unsuited for these joints by resulting in $P_{\mathrm{m}}$ much above the experiments. The relative deviations showed a decreasing trend by increasing $t_{\mathrm{p} 2}$, thus giving a maximum offset of $+140.5 \%$ for $t_{\mathrm{p} 2}=1 \mathrm{~mm}$ and a minimum offset of $+95.1 \%$ for $t_{\mathrm{p} 2}=4 \mathrm{~mm}$. For this and the subsequent adhesives, this large difference is justified by the higher failure displacements resulting from the exponential damage laws, which artificially enlarge the damage length in the adhesive. Analysis of the Araldite ${ }^{\circledR} 2015$ data denotes almost superimposed $P_{\mathrm{m}}$ predictions between $\alpha=1$ and 2 , and also good correlations to the experiments (maximum deviations of $-8.9 \%$ for $t_{\mathrm{P} 2}=4 \mathrm{~mm}$, considering $\alpha=1$, and $-8.3 \%$ for $t_{\mathrm{P} 2}=4 \mathrm{~mm}$, applying $\left.\alpha=2\right)$. Identically to the former adhesive, the exponential propagation law presented much higher $P_{\mathrm{m}}$ values than the experiments (up to $+117.7 \%$ for $t_{\mathrm{p} 2}=1$ $\mathrm{mm}$, again showing an offset reduction tendency by increasing $t_{\mathrm{p} 2}$ ). The effect of $\alpha$ on the XFEM results for the Sikaforce ${ }^{\circledR} 7752$ was the smallest between tested adhesives. It was found in a previous work [32] that this influence diminished by increasing the adhesive ductility, which also agrees with the results presented here. For this adhesive, the best results were again found with $\alpha=1$ and $2 \mathrm{~mm}$, with the $\alpha=0.5$ values falling short over the former. Nonetheless, compared against the experiments, there was a slightly higher under prediction tendency, which attained $-19.4 \%$ for $t_{\mathrm{p} 2}=4 \mathrm{~mm}(\alpha=0.5)$, $-13.3 \%$ for $t_{\mathrm{P} 2}=4 \mathrm{~mm}(\alpha=1)$ and $-12.7 \%$ for $t_{\mathrm{P} 2}=4 \mathrm{~mm}(\alpha=2)$. The exponential promoted offsets up to $+181.4 \%\left(t_{\mathrm{p} 2}=2\right.$ $\mathrm{mm})$, although here the reduction trend with $t_{\mathrm{P} 2}$ is not clear.

\section{ConClusions}

7 his work presented an experimental and numerical assessment of the behaviour of adhesively-bonded T-joints between aluminium adherends, considering different geometric conditions (tp2) and adhesives with different characteristics with respect to the strength and ductility. The experimental analysis showed that, for the particular joints conditions tested, i.e., a predominantly peel loading with major peak stresses, the most ductile although less strong Sikaforce ${ }^{\circledR} 7752$ is the one that presents better results for all $t_{\mathrm{p} 2}$. Increasing $t_{\mathrm{p} 2}$ highly increased $P_{\mathrm{m}}$ for all adhesives. The difference between adhesives was clarified by a $\sigma_{\mathrm{y}}$ and $\tau_{\mathrm{xy}}$ stress analysis being performed to the adhesive layer, which showed that the $\sigma_{\mathrm{y}}$ peak stresses ruling the failure process are inversely proportional to the adhesives' stiffness. Thus, the corresponding stress plots are more uniform and enable spreading the loads more evenly, which highly benefits $P_{\mathrm{m}}$. Adding to this, the Sikaforce ${ }^{\circledR} 7752$ is highly ductile, thus permitting the adhesive to undergo plasticization at the highest stresses zones, whilst lightly loaded regions increase load transfer, before failure. The damage variable analysis also supported the experimental findings, showing an increasing portion of damaged length of adhesive at $P_{\mathrm{m}}$ with the increase of $t_{\mathrm{P} 2}$, for all adhesives. This tends to bring a higher joint efficiency because the adhesive region resisting pull-out increases. The comparison between the three adhesives showed that the brittleness of the Araldite ${ }^{\circledR}$ AV138 leads to a much localised portion of the adhesive layer under damage at the time $P_{\mathrm{m}}$ is reached in the T-joints. The damage evolution was more gradual for the other adhesives, due to their inherent ductility, especially for the Sikaforce ${ }^{\circledR} 7752$. Higher damage zones should help in attaining higher $P_{\mathrm{m}}$ in this particular joint configuration that traditionally concentrates the load in a small portion of the adhesive. The XFEM analysis applied to the initiation criterion enabled to conclude that, for all the adhesives, the QUADS and MAXS criteria were the most adequate. The MAXPS criterion was inadequate, in view of the simplification taken to estimate $P_{\mathrm{m}}$. All strain-based criteria (QUADE, MAXE and MAXPE) overshot $P_{\mathrm{m}}$ by a large amount for the three adhesives, and should not be considered as well. The XFEM propagation law analysis showed good results for the triangular damage law for all adhesives, and the unsuitability of the exponential law. Between the different $\alpha$ for the triangular law, $\alpha=1$ and 2 generally provided closer results than $\alpha=0.5$.

\section{REFERENCES}

[1] Petrie, E.M. Handbook of adhesives and sealants. New York: McGraw-Hill; 2000.

[2] Akpinar, S. (2014). The strength of the adhesively bonded step-lap joints for different step numbers. Compos: Part B.67, pp. 170-178. DOI: 10.1016/j.compositesb.2014.06.023. 
[3] Di Bella, G., Borsellino, C., Pollicino, E., Ruisi, V.F. (2010). Experimental and numerical study of composite T-joints for marine application. Int J Adhes Adhes. 30, pp. 347-358. DOI: 10.1016/j.ijadhadh.2010.03.002.

[4] Trask, R.S., Hallett, S.R., Helenon, F.M.M., Wisnom, M.R. (2012). Influence of process induced defects on the failure of composite T-joint specimens. Composites Part A: Applied Science and Manufacturing. 43, pp. 748-757. DOI: 10.1016/j.compositesa.2011.12.021.

[5] Bianchi, F., Koh, T.M., Zhang, X., Partridge, I.K., Mouritz, A.P. (2012). Finite element modelling of z-pinned composite T-joints. Compos Sci Technol. 73, pp. 48-56. DOI: 10.1016/j.compscitech.2012.09.008.

[6] Burns, L.A., Mouritz, A.P., Pook, D., Feih, S. (2012). Bio-inspired design of aerospace composite joints for improved damage tolerance. Compos Struct.94, pp. 995-1004. DOI: 10.1016/j.compstruct.2011.11.005.

[7] Yang, T., Zhang, J., Mouritz, A.P., Wang, C.H. (2013). Healing of carbon fibre-epoxy composite T-joints using mendable polymer fibre stitching. Compos: Part B.45, pp. 1499-1507. DOI: 10.1016/j.compositesb.2012.08.022.

[8] Duan, K., Hu, X., Mai, Y.-W. (2004). Substrate constraint and adhesive thickness effects on fracture toughness of adhesive joints. J Adhes Sci Technol.18, pp. 39-53. DOI: 10.1163/156856104322746992.

[9] Panigrahi, S.K., Pradhan, B. (2007). Three Dimensional Failure Analysis and Damage Propagation Behavior of Adhesively Bonded Single Lap Joints in Laminated FRP Composites. Journal of Reinforced Plastics and Composites.26, pp. 183-201. DOI: 10.1177/0731684407070026.

[10] Weißgraeber, P.a.W.B. Crack Initiation at Weak Stress Singularities - Finite Fracture Mechanics Approach: Procedia Materials Science; 2014.

[11] da Silva, L.F.M., Campilho, R.D.S.G. Advances in numerical modelling of adhesive joints. Heidelberg: Springer; 2012.

[12] Yang, Q.D., Thouless, M.D. (2001). Mixed-mode fracture analyses of plastically-deforming adhesive joints. Int J Fract.110, pp. 175-187. DOI: 10.1023/A:1010869706996.

[13] Khoramishad, H., Crocombe, A.D., Katnam, K.B., Ashcroft, I.A. (2010). Predicting fatigue damage in adhesively bonded joints using a cohesive zone model. International Journal of Fatigue 32, pp. 1146-1158. DOI: $10.1016 /$ j.ijfatigue.2009.12.013.

[14] Daudeville, L., Ladevèze, P. (1993). A damage mechanics tool for laminate delamination. Compos Struct. 25, pp. 547555. DOI: 10.1016/0263-8223(93)90203-3.

[15] Voyiadjis, G.Z., Kattan, P.I. Damage Mechanics. New York: Marcell Dekker; 2005.

[16] Raghavan, P., Ghosh, S. (2005). A continuum damage mechanics model for unidirectional composites undergoing interfacial debonding. Mechanics of Materials. 37, pp. 955-979. DOI: 10.1016/j.mechmat.2004.10.003.

[17] Imanaka, M., Hamano, T., Morimoto, A., Ashino, R., Kimoto, M. (2003). Fatigue damage evaluation of adhesively bonded butt joints with a rubber-modified epoxy adhesive. J Adhes Sci Technol. 17, pp. 981-994.

DOI: $10.1163 / 156856103322112888$.

[18] Wahab, M.M.A., Ashcroft, I.A., Crocombe, A.D., Shaw, S.J. (2001). Prediction of fatigue thresholds in adhesively bonded joints using damage mechanics and fracture mechanics. J Adhes Sci Technol.15, pp. 763-781. DOI: $10.1163 / 15685610152540830$.

[19] Mohammadi, S. Extended finite element method for fracture analysis of structures. New Jersey, USA: Blackwell Publishing; 2008.

[20] Moës, N., Dolbow, J., Belytschko, T. (1999). A finite element method for crack growth without remeshing. Int J Numer Meth Eng.46, pp. 131-150. DOI: 10.1002/(SICI)1097-0207(19990910)46:1<131::AID-NME726>3.0.CO;2-J.

[21] Mubashar, A., Ashcroft, I.A., Crocombe, A.D. (2014). Modelling damage and failure in adhesive joints using a combined XFEM-cohesive element methodology. J Adhesion.90, pp. 682-697. DOI: 10.1080/00218464.2013.826580.

[22] Stuparu, F., Constantinescu, D.M., Apostol, D.A., Sandu, M. (2016). A Combined Cohesive Elements-XFEM Approach for Analyzing Crack Propagation in Bonded Joints. J Adhesion.92, pp. 535-552.

DOI: $10.1080 / 00218464.2015 .1115355$.

[23] Campilho, R.D.S.G., Banea, M.D., Pinto, A.M.G., da Silva, L.F.M., de Jesus, A.M.P. (2011). Strength prediction of single- and double-lap joints by standard and extended finite element modelling. Int J Adhes Adhes.31, pp. 363-372. DOI: 10.1016/j.ijadhadh.2010.09.008.

[24] Campilho, R.D.S.G., Banea, M.D., Neto, J.A.B.P., da Silva, L.F.M. (2013). Modelling adhesive joints with cohesive zone models: effect of the cohesive law shape of the adhesive layer. Int J Adhes Adhes.44, pp. 48-56.

DOI: 10.1016/j.ijadhadh.2013.02.006.

[25] Faneco, T., Campilho, R., Silva, F., Lopes, R. (2017). Strength and Fracture Characterization of a Novel Polyurethane Adhesive for the Automotive Industry. J Test Eval.45, pp. 398-407. DOI: 10.1520/JTE20150335.

[26] Campilho, R.D.S.G., Pinto, A.M.G., Banea, M.D., Silva, R.F., da Silva, L.F.M. (2011). Strength Improvement of Adhesively-Bonded Joints Using a Reverse-Bent Geometry. J Adhes Sci Technol.25, pp. 2351-2368. 
DOI: $10.1163 / 016942411 X 580081$.

[27] Nunes, S.L.S., Campilho, R.D.S.G., da Silva, F.J.G., de Sousa, C.C.R.G., Fernandes, T.A.B., Banea, M.D., et al. (2016). Comparative failure assessment of single and double-lap joints with varying adhesive systems. J Adhesion.92, pp. 610634. DOI: $10.1080 / 00218464.2015 .1103227$.

[28] Fernandes, T.A.B., Campilho, R.D.S.G., Banea, M.D., da Silva, L.F.M. (2015). Adhesive selection for single lap bonded joints: Experimentation and advanced techniques for strength prediction. J Adhesion.91, pp. 841-862. DOI: $10.1080 / 00218464.2014 .994703$.

[29] Pike, M.G., Oskay, C. (2015). XFEM modeling of short microfiber reinforced composites with cohesive interfaces. Finite Elem Anal Des.106, pp. 16-31. DOI: 10.1016/j.finel.2015.07.007.

[30] Abaqus ${ }^{\circledR}$. Documentation of the software Abaqus®. Dassault Systèmes. Vélizy-Villacoublay 2013.

[31] de Sousa, C.C.R.G., Campilho, R.D.S.G., Marques, E.A.S., Costa, M., da Silva, L.F.M. (2017). Overview of different strength prediction techniques for single-lap bonded joints. J Mater Des Appl - L.231, pp. 210-223. DOI: $10.1177 / 1464420716675746$.

[32] Xará, J.T.S., Campilho, R.D.S.G. (2018). Strength estimation of hybrid single-L bonded joints by the eXtended Finite Element Method. Compos Struct.183, pp. 397-406. DOI: 10.1016/j.compstruct.2017.04.009. 